Subscriber access provided by University of East Anglia Library

\title{
Article
}

\section{A Fluorescent Probe Identifies Active Site Ligands of Inositol Pentakisphosphate 2-Kinase}

Hayley Whitfield, Megan Gilmartin, Kendall Baker, Andrew M Riley, Himali Y Godage, Barry V. L. Potter, Andrew M. Hemmings, and Charles A Brearley

J. Med. Chem., Just Accepted Manuscript • DOI: 10.1021/acs.jmedchem.8b01022 • Publication Date (Web): 30 Aug 2018

Downloaded from http://pubs.acs.org on August 31, 2018

\section{Just Accepted}

"Just Accepted" manuscripts have been peer-reviewed and accepted for publication. They are posted online prior to technical editing, formatting for publication and author proofing. The American Chemical Society provides "Just Accepted" as a service to the research community to expedite the dissemination of scientific material as soon as possible after acceptance. "Just Accepted" manuscripts appear in full in PDF format accompanied by an HTML abstract. "Just Accepted" manuscripts have been fully peer reviewed, but should not be considered the official version of record. They are citable by the Digital Object Identifier (DOI®). "Just Accepted" is an optional service offered to authors. Therefore, the "Just Accepted" Web site may not include all articles that will be published in the journal. After a manuscript is technically edited and formatted, it will be removed from the "Just Accepted" Web site and published as an ASAP article. Note that technical editing may introduce minor changes to the manuscript text and/or graphics which could affect content, and all legal disclaimers and ethical guidelines that apply to the journal pertain. ACS cannot be held responsible for errors or consequences arising from the use of information contained in these "Just Accepted" manuscripts. 


\title{
A Fluorescent Probe Identifies Active Site Ligands of Inositol
}

\section{Pentakisphosphate 2-Kinase}

Hayley Whitfield ${ }^{\dagger}$, Megan Gilmartin $^{\dagger}$, Kendall Baker $^{\dagger}$, Andrew M Riley $^{\ddagger}$, Himali Y

Godage $^{+}$, Barry VL Potter ${ }^{\ddagger+}$, Andrew M Hemmings ${ }^{\dagger}$, Charles A Brearley $^{+*}$

${ }^{\dagger}$ School of Biological Sciences, University of East Anglia, Norwich Research Park, Norwich NR4 7TJ, UK.

${ }^{\ddagger}$ Medicinal Chemistry \& Drug Discovery, Department of Pharmacology, University of Oxford, Mansfield Road, Oxford OX1 3QT, UK

${ }^{+}$Medicinal Chemistry, Department of Pharmacy and Pharmacology, University of Bath, Claverton Down, Bath BA2 7AY, UK

\begin{abstract}
Inositol pentakisphosphate 2-kinase catalyzes the phosphorylation of the axial 2-OH of myo-inositol 1,3,4,5,6-pentakisphosphate for de novo synthesis of myo-inositol hexakisphosphate. Disruption of inositol pentakisphosphate 2-kinase profoundly influences cellular processes; from nuclear mRNA export and phosphate homeostasis in yeast and plants, to establishment of left-right asymmetry in zebra fish. We elaborate an active site fluorescent probe that allows high throughput screening of Arabidopsis inositol pentakisphosphate 2-kinase. We show that the probe has a binding constant comparable to the $\mathrm{K}_{\mathrm{m}}$ values of inositol phosphate substrates of this enzyme, and can be
\end{abstract}


used to prospect for novel substrates and inhibitors of inositol phosphate kinases. We identify several micromolar $\mathrm{K}_{\mathrm{i}}$ inhibitors and validate this approach by solving the crystal structure of protein in complex with purpurogallin. We additionally solve structures of protein in complexes with epimeric higher inositol phosphates. This probe may find utility in characterization of a wide family of inositol phosphate kinases.

\section{INTRODUCTION}

Inositol pentakisphosphate 2-kinase (IP5 2-K) catalyzes the phosphorylation of the axial 2-hydroxyl of myo-inositol 1,3,4,5,6-pentakisphosphate ${ }^{1}$ and its deletion in mice is embryo lethal ${ }^{2}$. The single yeast ortholog, named IPK1, was identified as one of three genes that complement a synthetic lesion in mRNA export from the yeast nucleus ${ }^{3}$, a phenotype that has been confirmed in plants ${ }^{4}$. Knockdown of the gene disrupts left-right asymmetry in zebrafish ${ }^{5}$ and in plants disruption reduces the accumulation of inositol hexakisphosphate in vegetative and storage tissues ${ }^{6}$, where it accumulates to several percent of seed dry weight ${ }^{7}$. More recently, inositol pentakisphosphate 2-kinase has received considerable attention as the enzyme responsible for the metabolic connection between receptor-activated inositol phosphate metabolism and the metabolism of an emergent class of signaling molecule, the diphosphoinositol phosphates ${ }^{8}$, albeit a class of molecule described in the early 90 's ${ }^{9}$. In yeast, disruption of IPK1 leads to the accumulation of PP- $\mathrm{InsP}_{4}{ }^{10}$, a molecule not identified in plants.

While the study of inositol pentakisphosphate 2-kinase has been aided by high resolution description of crystal structure for plant ${ }^{11,12}$ and mammalian ${ }^{13}$ enzymes which elucidate 
folding motions that accompany catalysis ${ }^{11,12,14,15}$, probes of the active site have yet to be described. This limits study to coupled enzyme assays ${ }^{12,15}$, to end-point assays ${ }^{11}$ or assays that demand HPLC separation of products, commonly radiolabeled ${ }^{16}$. The latter two approaches do not allow for real-time measurement, while the former is easily confounded by interferences. An additional complication is the lack of known inhibitors of the enzyme, something that could be obviated with development of a high-throughput screening method. Here we report a small molecule active site probe of Arabidopsis thaliana inositol pentakisphosphate 2-kinase (AtIP5 2-K) which may find utility in characterization of this family of enzymes.

Fluorescent derivatives of phosphoinositides have been exploited in commercial assays of phosphoinositide phosphatases. In one such assay, the $\operatorname{PtdIns}(3,4) \mathrm{P}_{2}$ product of end-point 5-dephosphorylation of PtdIns $(3,4,5) \mathrm{P}_{3}$, when added to a synthetic BODIPY-tagged PtdIns $(3,4) \mathrm{P}_{2}$, competes for binding to a PtdIns $(3,4) \mathrm{P}_{2}$-specific binding protein, assayed by change in fluorescence anisotropy or polarization ${ }^{17}$. We rationalized that a fluorescent - tagged inositol pentakisphosphate, 2-FAM-InsP ${ }_{5}{ }^{18}$ may, in contrast, work directly as an active-site ligand for inositol phosphate kinases that accommodate inositide and nucleotide co-substrates in relatively large (volume) active sites or in enzymes such as inositol pentakisphosphate 2-kinase which show ligand-induced folding motions that accompany catalysis ${ }^{14,15}$. To date, this and similar molecules have been used only as ligands of inositol phosphate-binding proteins such as the $\mathrm{IP}_{3}$ receptor ${ }^{19}$ and the histone deacetylase, HDAC4, which binds D-Ins $(1,4,5,6) \mathrm{P}_{4}$ between itself and its cognate partner ${ }^{20}$. We further rationalized that IP5 2-K, which lacks phosphatase activity ${ }^{21}$, would, in 
the absence of nucleotide, be unable to dephosphorylate the fully substituted inositol ring of the probe or phosphorylate it. Among proteins with inositol phosphate kinase or diphosphoinositol phosphate kinase activity, dephosphorylation of the fully phosphatesubstituted ring is the exclusive catalytic property of inositol hexakisphosphate kinase ${ }^{22}$ and diphosphoinositol phosphate kinase, the latter additionally possessing a distinct phosphatase domain $^{23,24}$.

\section{RESULTS AND DISCUSSION}

\section{2-FAM-InsP 5 binds to AtIP5 2-K}

2-FAM-InsP ${ }_{5}$ was incubated at $25{ }^{\circ} \mathrm{C}$ for 10 min with AtIP5 2-K and polarization of the probe measured as a function of protein concentration (Figure 1B). The increase in polarization from a machine-set value of $35 \mathrm{mP}$ for unbound probe was fitted to a 4parameter logistic function yielding an EC50 of $63 \pm 0.6$ (mean, se) nM for AtIP5 2-K. 
a
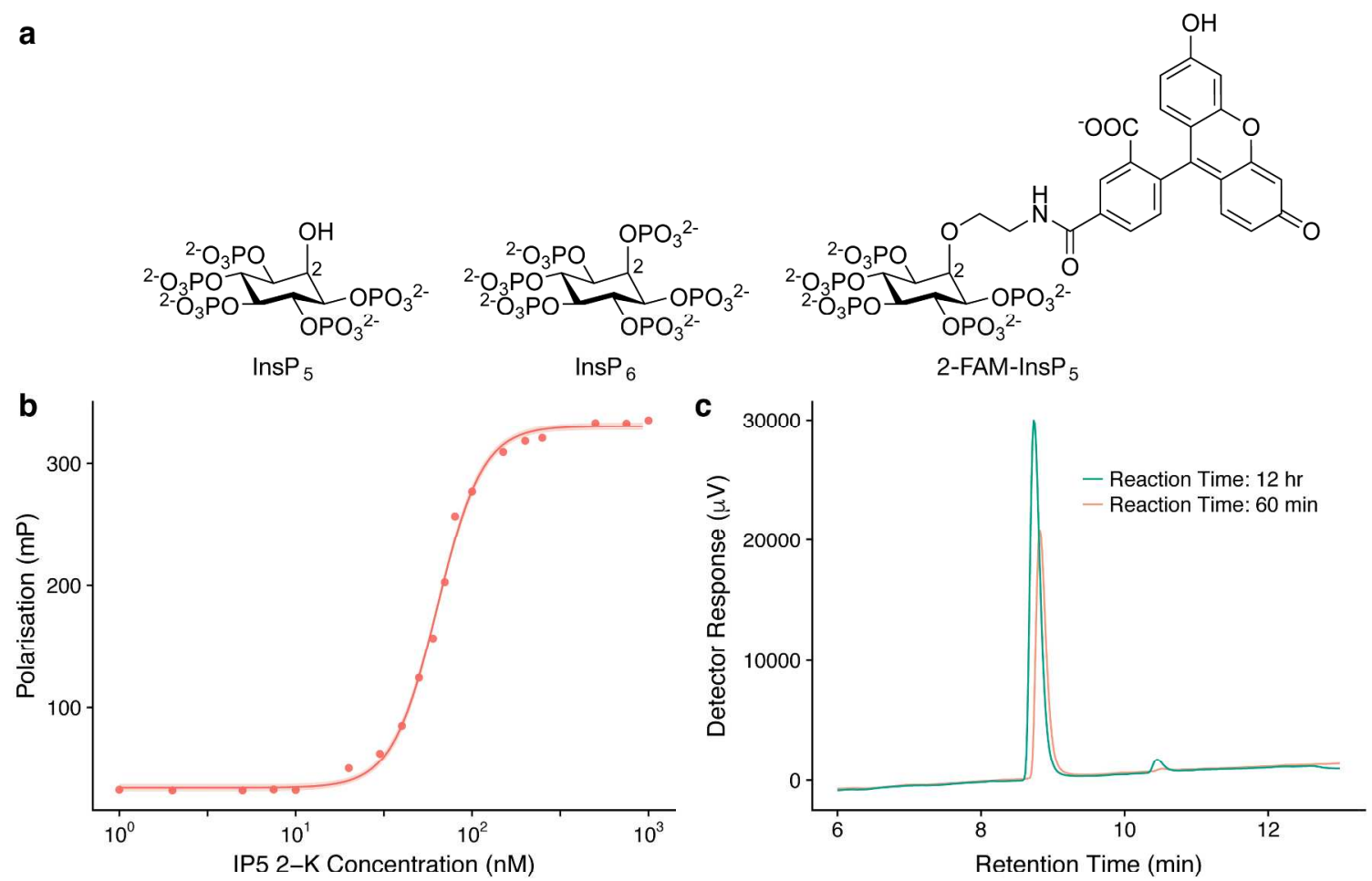

d
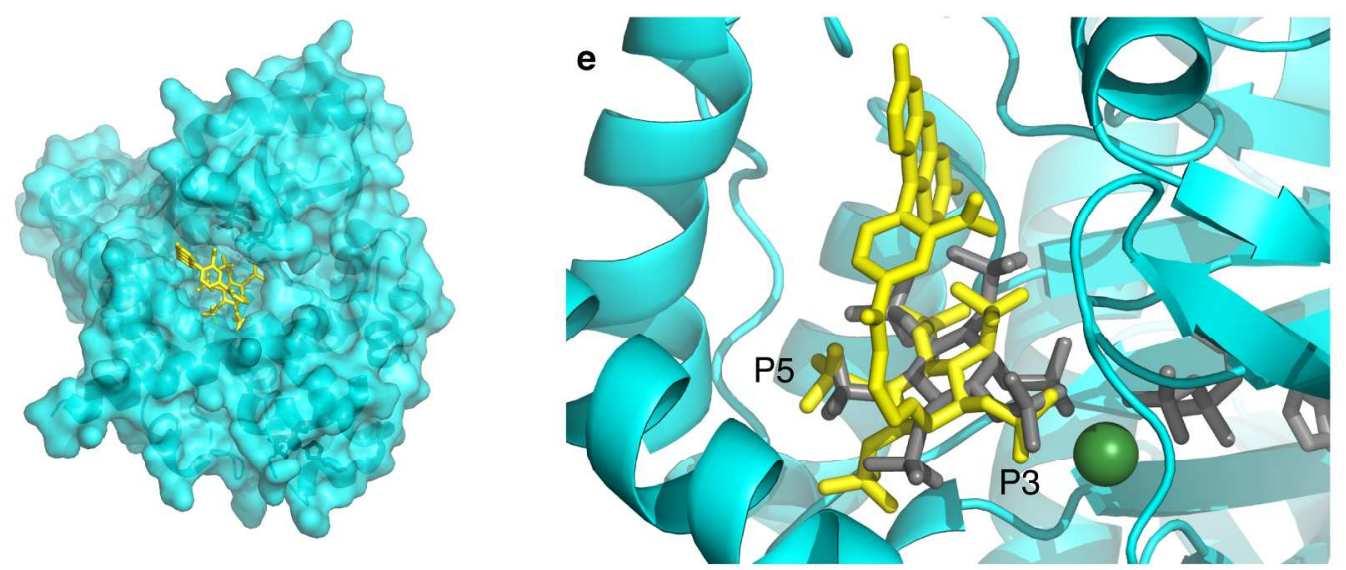

Figure 1. 2-FAM-IP ${ }_{5}$ is an active site ligand of AtIP5 2-K. (A) structures of myo-Ins $(1,3,4,5,6) P_{5}$ (Ins $\left.P_{5}\right)$, myo-Ins $P_{6}$ and 2-FAM-InsP $P_{5}$ (B) Binding of 2-FAM-IP 5 to AtIP5 2-K followed by increase of fluorescence polarization of 2-FAM-IP, $95 \%$ confidence limits shown by shading around line of best fit. Data was plotted with ggplot2 in $R^{25}$. (C) AtIP5 2-K catalyzed phosphotransfer from 2-FAM-IP ${ }_{5}$ to ADP; ADP elutes at approx.8. 7 min, ATP at approx. 10.4 min. (D) Surface representation of the closed conformation of AtIP5 2-K (PDB 2XAM) (cyan) ${ }^{12}$ 
used as a receptor for docking of 2-FAM-IP 5 (yellow). (E) Close-up of the active site of AtIP5 2-K (cyan) showing lowest energy docked conformation of 2-FAM-IP 5 (yellow) overlaid with the crystallographically-determined position of myo-Ins $P_{6}$ (black). The positions of $A D P$ (black) and magnesium (green) were fixed during docking.

We performed similar experiments with the structurally-related potato multikinase StIPMK ${ }^{26}$ and the unrelated kinase AtITPK4, an Arabidopsis inositol 1,3,4-trisphosphate 5/6-kinase ${ }^{27}$. These experiments gave EC50 values of $40 \pm 2 \mathrm{nM}$ with a $1 \mathrm{nM}$ probe concentration for StIPMK, and $12.6 \pm 0.02 \mu \mathrm{M}$ with $10 \mathrm{nM}$ probe concentration for AtITPK4. For AtIP5 2-K, transformation of polarization to fraction bound yielded $\mathrm{K}_{\mathrm{d}}=$ $0.26 \mu \mathrm{M}$ (Supporting Information Figure 1). This value is considerably lower than the $\mathrm{K}_{\mathrm{m}}\left(22 \mu \mathrm{M} \text { for } \operatorname{InsP}_{5}\right)^{21}$, but is similar to the $\mathrm{K}_{\mathrm{d}}\left(\right.$ for $\left.\operatorname{InsP}_{5}\right)$ of $0.6 \mu \mathrm{M}$ obtained by isothermal calorimetry ${ }^{14}$. 2-FAM-InsP ${ }_{5}$ was clearly a poorer probe for AtITPK4, a protein whose presumed ATP-grasp structural fold is shared not only with plant ITPKs that show phosphotransferase activity ${ }^{29}$, but also with mammalian (PPIP5K), and yeast/plant diphosphoinositol phosphate kinases ${ }^{24,28}$.

\section{2-FAM-InsP $P_{5}$ is an active site ligand of AtIP5 2-K}

As the inositol moiety lacks a free hydroxyl group that might provide a site for phosphorylation, we tested whether the probe was a substrate for the inositol phosphateADP phosphotransferase activity of AtIP5 2-K ${ }^{1}$. Incubation of enzyme with 2-FAM$\mathrm{InsP}_{5}$ and ADP revealed a time- and 2-FAM-InsP $\mathrm{P}_{5}$-dependent conversion of ADP to ATP monitored by HPLC by increase of ATP (Figure 1C). Thus, despite the absence of an 
axial phosphate, the molecule is a substrate for phosphotransfer to ADP as acceptor; though the reaction was considerably slower than that using $\operatorname{Ins}_{6}$ substrate, yielding $0.82 \%$ and $3.3 \%$ conversion of ADP to ATP for 2-FAM-InsP $P_{5}$ and $\operatorname{InsP}_{6}$, respectively, over $12 \mathrm{~h}$. We posit that the protein-ligand interactions required for accommodation of the planar fluorescein moiety of the 2-FAM-Ins $\mathrm{P}_{5}$ force one or more equatorial phosphates into positions which allow catalysis. In the presence of ATP, the enzyme did not phosphorylate the probe (data not shown). In an attempt to confirm that 2-FAM-InsP ${ }_{5}$ binds to the active site of AtIP5 2-K we undertook extensive cocrystallization and ligand soaking experiments, but were unsuccessful.

\section{In silico docking supports active site binding of 2-FAM-Ins $\mathrm{P}_{5}$}

Since crystallographic data confirming the binding of 2-FAM-InsP $\mathrm{P}_{5}$ to AtIP5 2-K proved elusive, we turned to in silico docking to predict the binding of this large ligand in the active site of the enzyme. The three known conformers of AtIP5 2-K, open (PDB 4AXC), half-closed (PDB 4AXE) and closed (PDB 2XAM), were used as receptor structures in separate docking calculations employing 2-FAM-Ins $\mathrm{P}_{5}$ as a flexible ligand. The lowest energy binding pose predicted for the closed conformer indicated that the inositol ring binds in a similar position and orientation to that of $m y o-\mathrm{InsP}_{6}$, such that the 1D-P3 and 1D-P5 positions are conserved (Figure 1D, E). This positioning of the inositol phosphate moiety was also observed in four other binding poses within $0.5 \mathrm{kcal} \mathrm{mol}^{-1}$ of the lowest energy pose (Supporting Information Figure 2). These four poses place a phosphate group close to the (myo-InsP $\mathrm{P}_{6}$ ) 1D-P4 and 1D-P6 positions, with 1D-P1 and $\mathrm{P} 2$ positions unoccupied. In the lowest energy pose (Figure 1D), the FAM moiety is oriented such that it protrudes from the active site pocket between W129 ( $\alpha 6$ of the N lobe, for 


\begin{abstract}
nomenclature ${ }^{12}$ ) and E205 (CIP-I lobe ${ }^{12}$ ), suggesting the active site in the closed conformation can accommodate 2-FAM-InsP $\mathrm{P}_{5}$. Whilst the result of docking using the half-closed structure as receptor was consistent in terms of placement of the FAM moiety, the binding modes for the open (apo) structure were more variable and did not consistently place the inositol ring in the same position as that of $m y o-\mathrm{InsP}_{6}$ (Supporting Information Figure 2).
\end{abstract}

\title{
AtIP5 2-K accommodates neo- and D-chiro-inositol hexakisphosphate substrates
}

Having determined 2-FAM-InsP ${ }_{5}$ to be an active site ligand, we sought to establish its utility in reporting the binding of other epimers of higher inositol phosphates to AtIP5 2$\mathrm{K}$, prior to prospecting for novel substrates of the enzyme. While highly phosphorylated isomers of other inositols are widespread in nature ${ }^{30}$, the underpinning enzymology is not described ${ }^{31}$. We initially tested the ability of a range of inositol phosphates to displace 2-FAM-InsP ${ }_{5}$ from AtIP5 2-K. Displacement of the probe was fitted to a 4parameter logistic (Figure 2). 
Figure 2. Displacement of 2-FAM-IP 5 binding to AtIP5 2-K by myo-Ins $P_{6}, D$-chiro-Ins $P_{6}$, neoIns $P_{6}$ and myo-Ins $(1,3,4,5,6) P_{5}, 95 \%$ confidence limits are shown. The structures of inositol phosphates are shown as Mills projections, with 1D-numbering of inositol ring carbon atoms.

The known kinase substrate myo-Ins $(1,3,4,5,6) \mathrm{P}_{5}$ and kinase product $m y o$-Ins $\mathrm{P}_{6}$ yielded EC50 values (mean, standard error) of $18 \pm 1$ and $959 \pm 1 \mathrm{nM}$, respectively, reflecting the acceptance of these molecules as substrates for kinase and phosphotransferase activities, respectively (Figure 3). AtIP5 2-K has been shown to phosphorylate the axial 2-hydroxyl of myo-inositol phosphate substrates, D-Ins $(1,4,5,6) \mathrm{P}_{4}, \mathrm{D}-\operatorname{Ins}(3,4,5,6) \mathrm{P}_{4}$, $\operatorname{Ins}(1,3,4,6) \mathrm{P}_{4}$ and $\operatorname{Ins}(1,3,4,5,6) \mathrm{P}_{5} 11,12,14,15,21$. We recently showed that neo-inositol 1,3,4,6-tetrakisphosphate and D-chiro-inositol 2,3,4,5-tetrakisphosphate are substrates for 
the kinase activity of AtIP5 2-K, while D-chiro-inositol 1,3,4,6-tetrakisphosphate is not 32 . The first possesses axial hydroxyls on the 2- and 5-positions, the second has axial hydroxyls on the 1- and 6-positions, while the third has no axial hydroxyls ${ }^{31}$. In the current study, D-chiro-InsP ${ }_{6}$ and neo-InsP ${ }_{6}$ displaced 2-FAM-InsP ${ }_{5}$ with EC50s of $4496 \pm$ $1 \mathrm{nM}$ and $>500 \pm 0.5 \mu \mathrm{M}$, respectively, (Figure 2) and proved to be substrates for inositol phosphate-ADP phosphotransferase activity (Figure 3).

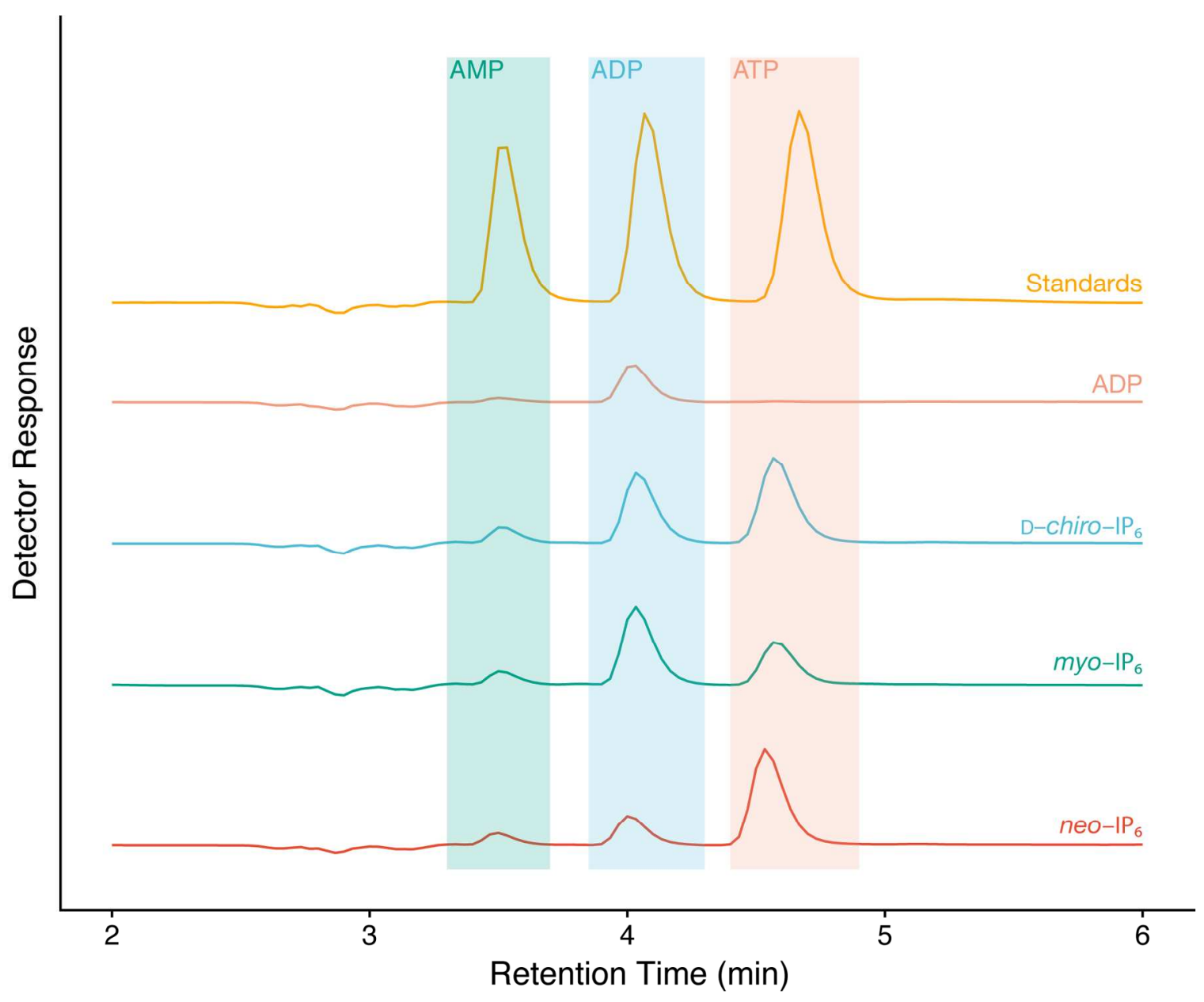

Figure 3. Myo-Ins $P_{6}, D$-chiro-Ins $P_{6}$ and neo-Ins $P_{6}$ are substrates of the inositol phosphate-ADP phosphotransferase activity of IP5 2-K. Inositol phosphate-dependent conversion of ADP to ATP was followed by HPLC of nucleotides. 


\section{Crystal structures of AtIP5 2-K in ternary complex with myo-, neo- and D-chiro- inositol phosphates}

To address the structural determinants of reactivity towards these novel substrates of the inositol phosphate-ADP phosphotransferase activity of AtIP5 2-K, we undertook cocrystallization experiments with these compounds in the presence of ADP. We are not aware that neo- and D-chiro-inositol phosphates have been identified as protein ligands in the PDB. Crystal structures were obtained in space group P1 at a resolution of $3.0 \AA$ for the complex with D-chiro-InsP 6 (PDB entry 6GFG) and at $2.65 \AA$ for $n e o-\operatorname{InsP}_{5}(6 \mathrm{GFH})$ (Figure 4 and Supporting Information Table 1). To provide reference points for analysis, we also solved the structures of the ternary complexes of AtIP5 2-K with myo-InsP ${ }_{6}$ and $\operatorname{ADP}(2.03 \AA$ resolution; PDB entry $6 \mathrm{FJK})$ and with $m y o-\operatorname{InsP}_{5}$ and $\mathrm{ADP}(2.36 \AA$ resolution; PDB entry 6FL3). 


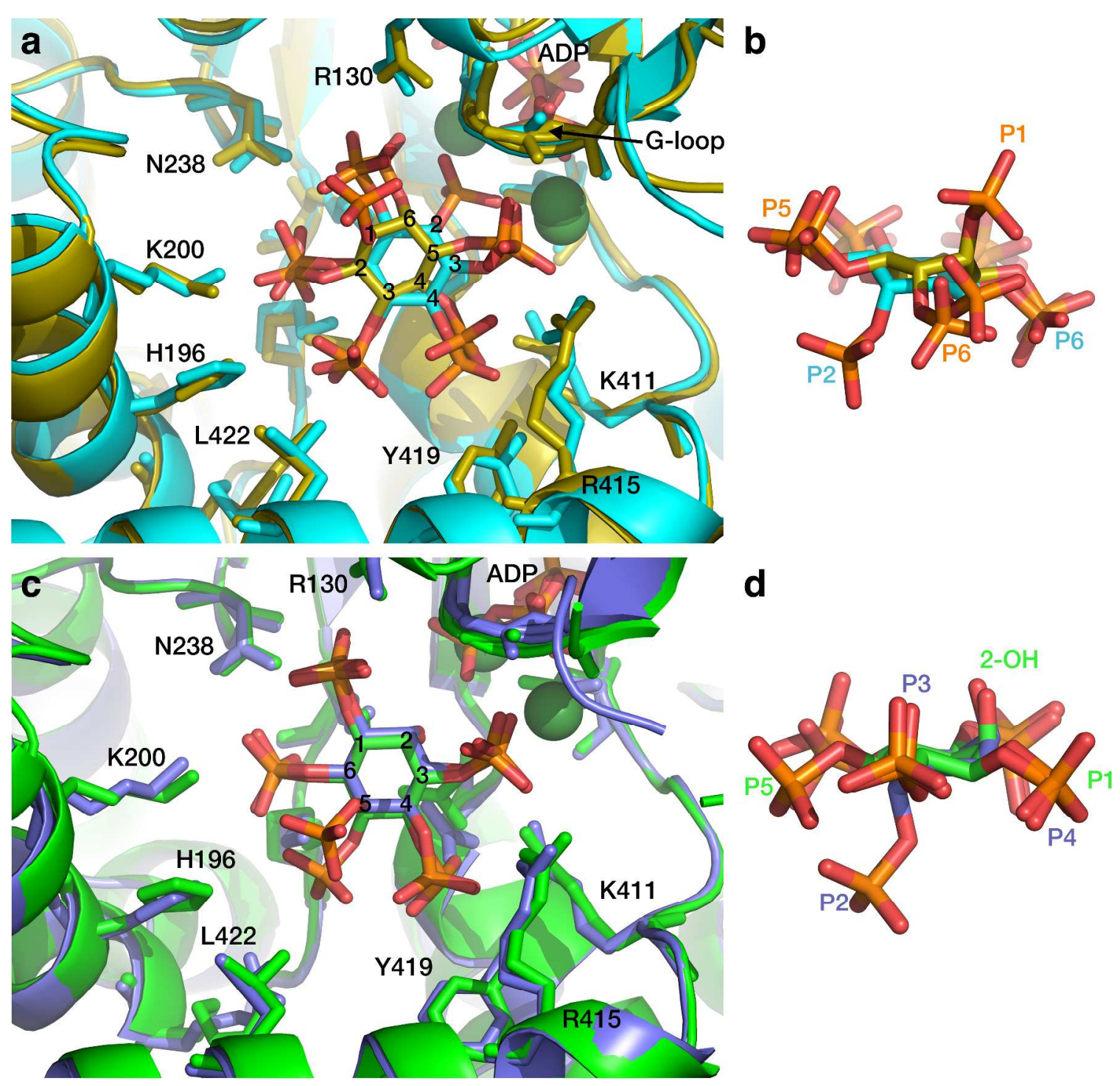

Figure 4. Ternary complexes of AtIP5 2-K with epimeric higher inositol phosphates. (A) Complex of AtIP5 2-K with ADP and myo-InsP 6 (cyan) overlaid with D-chiro-IP 6 (gold). (B) Orthogonal (to A) projection of myo-Ins $P_{6}$ (cyan) and D-chiro-Ins $P_{6}$ (gold) ligands. The numbering of carbons is shown for both ligands. (C) AtIP5 2-K with ATP and myoIns $(1,3,4,5,6) P_{5}$ (green) overlaid with neo-Ins $(1,3,4,5,6) P_{5}$ (purple), the numbering of carbons is shown for myo-InsP $P_{6}$ (D) Orthogonal (to C) projection of myo-Ins $(1,3,4,5,6) P_{5}$ (green) and 
neo-Ins $(1,3,4,5,6) P_{5}$ (purple) ligands. We use the common 1-D nomenclature for myo-Ins $P_{5}$ and myo-Ins $P_{6}$. The numbering of substituents on D-chiro-Ins $P_{6}$ is unequivocal, as is the numbering of substituents on neo-InsP $P_{5}$, however, because of symmetry elements neo$\operatorname{Ins}(1,3,4,5,6) P_{5}=n e o-\operatorname{Ins}(1,2,3,4,6) P_{5}$

These structures revealed no significant differences in the conformation of backbone atoms between each other, root mean square deviation (RMSD) $0.46 \AA$ over 400 common atoms (Supporting Information Table 2). Similarly, when PDB entry 6JFK was compared with that solved with the same ligands in space group $\mathrm{P} 2{ }_{1} 2_{1} 2_{1}{ }^{12}$ with a non-His-tagged form of the protein (PDB 4AQK), we obtained a RMSD $0.77 \AA$ with 398 common $\mathrm{C}_{\alpha}$ atoms (Supporting Information Table 2). The 12 contacts made with $m y o$-Ins $\mathrm{P}_{6}$ by active site residues (inositide contacts) and 18 with ADP (nucleotide contacts) are conserved in the D-chiro- $\mathrm{InsP}_{6-}$ and neo-InsP $\mathrm{P}_{5}$-liganded structures (contact residues are defined in Supporting Information Table 3). In the structure of the complex with myoIns $(1,3,4,5,6) \mathrm{P}_{5}$ and ADP, the 5-phosphate group of the inositide ligand, unlike the other phosphates, makes only a single amino acid contact with the enzyme, this being with the sidechain of Lys170, whilst its other contacts are to water molecules.

Crystallization of the enzyme with D-chiro- $\operatorname{InsP}_{6}$ and ADP yielded clear electron density accommodating both the coenzyme and ligand in each of the two monomers of the enzyme found in the crystallographic asymmetric unit (Figure 4 A,B and Supporting Information Figures 3,4). The two adjacent axial 1- and 6- phosphates of the ligand broadly occupy the position observed for the D-1-phosphate in the complex with myoInsP $_{6}$, liganded to Arg130. Only minor differences in enzyme conformation were observed between the D-chiro-InsP $\mathrm{P}_{6}$ and $m y o$-Ins $\mathrm{P}_{6}$ complexes (RMSD $0.42 \AA$ over 296 
residues of the N-I and C-lobes, and $0.48 \AA$ over the entire protein, 391 residues (Supporting Information Table 2). The positions of ligand- and coenzyme-binding residues were also preserved: the RMSD for inositide contact residues was $0.42 \AA$ whilst that for nucleotide contact residues was $0.25 \AA$ (Supporting Information Table 4).

For crystals grown in the presence of $n e o-\mathrm{InsP}_{6}$ and ADP, difference electron density maps revealed neo-inositol 1,2,3,4,6-pentakisphosphate $\left[\right.$ neo-Ins $(1,2,3,4,6) \mathrm{P}_{5}=$ neo$\operatorname{Ins}(1,3,4,5,6) \mathrm{P}_{5}$ ] bound similarly in both active sites. In addition, residual difference electron density and omit maps indicated not ADP but ATP bound as coenzyme, presumably arising from phosphotransfer between neo-InsP ${ }_{6}$ and ADP (Figure 4 C,D and Supporting Information Figures 3C, 4C). No significant difference in the conformation of backbone residues was observed between the neo-InsP $\mathrm{P}_{5}$ and $m y o-\mathrm{InsP}_{6}$ complexes (RMSD $0.53 \AA$ over 298 residues of the N-I and C-lobes and $0.56 \AA$ over the entire protein). Neo-InsP 6 possesses a $C 2$ axis of rotational symmetry that bisects the $\mathrm{C} 1-\mathrm{C} 6$ and C3-C4 bonds. Consequently, axial substituents P2 and P5 are superposable, as are equatorial $\mathrm{C} 1$ and $\mathrm{C} 6$, and $\mathrm{C} 3$ and $\mathrm{C} 4$. In the neo-inositol 1,2,3,4,6-pentakisphosphateliganded structure (PDB entry 6GFH), one of the axial positions $(5-\mathrm{OH})$, is apposed to the magnesium ion and ATP in a position occupied by the 2-hydroxyl group of myo$\mathrm{InsP}_{5}$ (PDB entry 6FL3). The orientation of the other axial position (of the neo-ligand), a phosphate (P2), is opposed to that of the equatorial 5-phosphate of myo- $\operatorname{InsP}_{5}$.

Comparison of the structures of complexes of AtIP5 2-K with myo-, neo- and D-chiroinositol phosphate ligands reveals, for the D-chiro- and neo- ligands, the conservation of interactions with Arg130 and Arg415 and the effective colocalization of the different inositol phosphate ligands (Fig. 4 A-D and Supplementary Information Figure 5). All 
enzyme-ligand complexes, also retain contacts between phosphate and at least two of the trio of lysines, Lys168, Lys 170 and Lys200, that co-ordinate P2 and 1D-P6, P5 and 1DP6, and 1D-P6 of myo-InsP 6 , respectively ${ }^{12,33}$, suggesting that these residues are major determinants of recognition of other (including epimeric) higher inositol phosphate substrates of the enzyme. Other residues that make contacts with myo- $\mathrm{InsP}_{6}$ are involved in recognition of neo-Ins $\mathrm{P}_{5}$ and/or D-chiro-InsP $\mathrm{P}_{6}$, albeit via contacts to differently numbered phosphates of the ligand (Supplementary Information Figure 5). Thus, Tyr419, which contacts $1 \mathrm{D}-\mathrm{P} 4$ in the $m y o$-InsP $\mathrm{P}_{6}$ complex, contacts $\mathrm{P} 3$ in the neo-Ins $\mathrm{P}_{5}$ complex, but lacks contacts in the D-chiro $\mathrm{InsP}_{6}$ complex. Arg4 15 contacts 1D-P3 and 1D-P4 (myo-) and contacts $\mathrm{P} 3$ and $\mathrm{P} 4$ in neo-InsP 5 and $\mathrm{P} 3$ in D-chiro-InsP $\mathrm{P}_{6}$. Lys170 which contacts P5 and 1D-P6 (myo-), contacts P1 (neo-) and P4 (D-chiro-); while Asn238 which contacts 1D-P1 and 1D-P6 (myo-) makes contact with P1 and P6 of the neo-ligand and P5 of the chiro-ligand.

\section{A High Throughput-compatible fluorescence polarization Screen (HTS) identifies novel AtIP5 2-K ligands}

The binding of 2-FAM-InsP 5 to AtIP5 2-K and its displacement by confirmed active site ligands affords the opportunity to identify novel active-site ligands. We therefore determined whether 2-FAM-InsP 5 and AtIP5 2-K could be used to develop an assay suitable for high-throughput screens. In the first instance we used 96-well microtiter plates to match the format of the NCI Diversity Set II, Developmental Therapeutics Program NCI/NIH, before developing assays in 384-well microtiter plates. Compounds were tested as singletons at $12.5 \mu \mathrm{M}$ concentration in $0.1 \% \mathrm{DMSO}$ for their ability to displace 2-FAM-InsP $5(5 \mathrm{nM})$ from $100 \mathrm{nM}$ protein in a $100 \mu \mathrm{L}$ volume. Control 
samples of unbound probe (with machine set value of $35 \mathrm{mP}$ ) and 'fully-bound' probe (reaching $350 \mathrm{mP}$ ) yielded a $Z^{\prime}$-factor ${ }^{34}$ of $>0.9$. An initial screen yielded a hit rate of $\approx$ $1 \%$ at polarization value $<150 \mathrm{mP}$, more than 9 standard deviations removed from the mean of the 'fully-bound' value (Figure 5). A number of initial 'hits' were discarded on analysis of their optical properties at the concentration used, either absorbance or fluorescence, or on subsequent preliminary dose-response analysis.

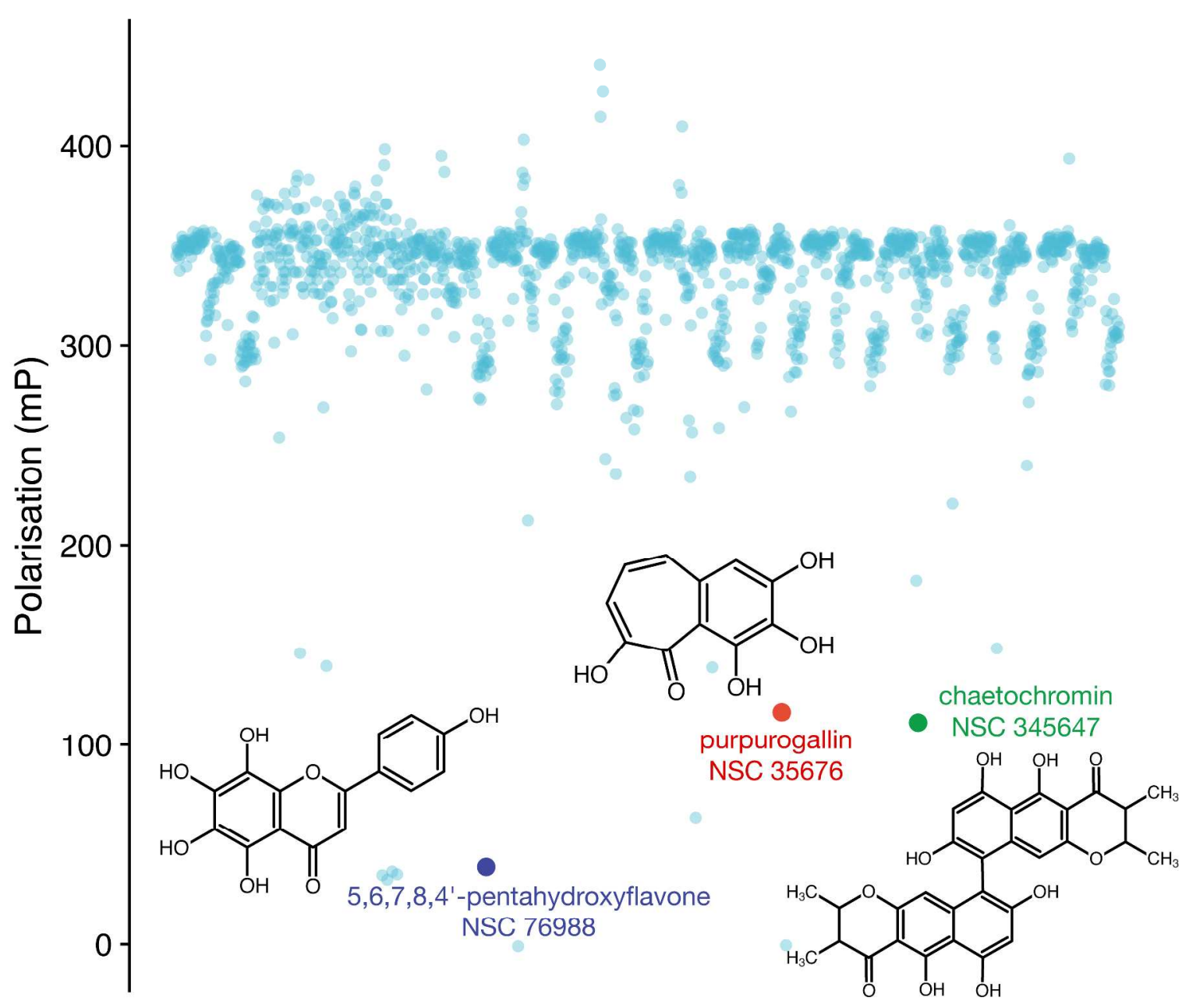

Figure 5. High Throughput-compatible Screen of IP5 2-K ligands. Anisotropy of AtIP5 2-K-

bound 2-FAM-IP5. The chemical structures of NCI Diversity Set II ligands carried forward to individual analysis are shown with the data points that identify them. 
Of the remainder, eight compounds were further ordered from the NCI DTP for follow up study: NSC 19063, NSC 35676, NSC 36815, NSC 107022, NSC 76988, NSC 37627, NSC 91529, and NSC 345647, and taken forward for initial dose-response analysis over 5 decades of concentration in the range $1 \mathrm{nM}-100 \mu \mathrm{M}$, before further refinement of the assay. These assays were performed in $20 \mu \mathrm{L}$ volume in 384 -well plates with $2 \mathrm{nM} 2-$ FAM-InsP $P_{5}$ and $200 \mathrm{nM}$ protein, quadruplicate samples were pipetted by hand.

Of these eight compounds, three (Figure 5): NCI 35676, purpurogallin, CAS\# 569-77-7, an aglcycone with similarity to catechol (1,2-dihydroxybenzene) and an inhibitor of catechol-O-methyltransferase ${ }^{35}$; NCI 76988, 5,6,7,8,4'-pentahydroxyflavone (nortangeretin), CAS\# 577-26-4 and NSC 345647, chaetochromin, CAS\# 75514-37-3, yielded $\mathrm{IC}_{50}$ (mean, standard error) of $3.7 \pm 1.0 \mu \mathrm{M}, 17.6 \pm 8.0 \mu \mathrm{M}$ and unestimable, respectively (Figure 6A). 


\section{a}
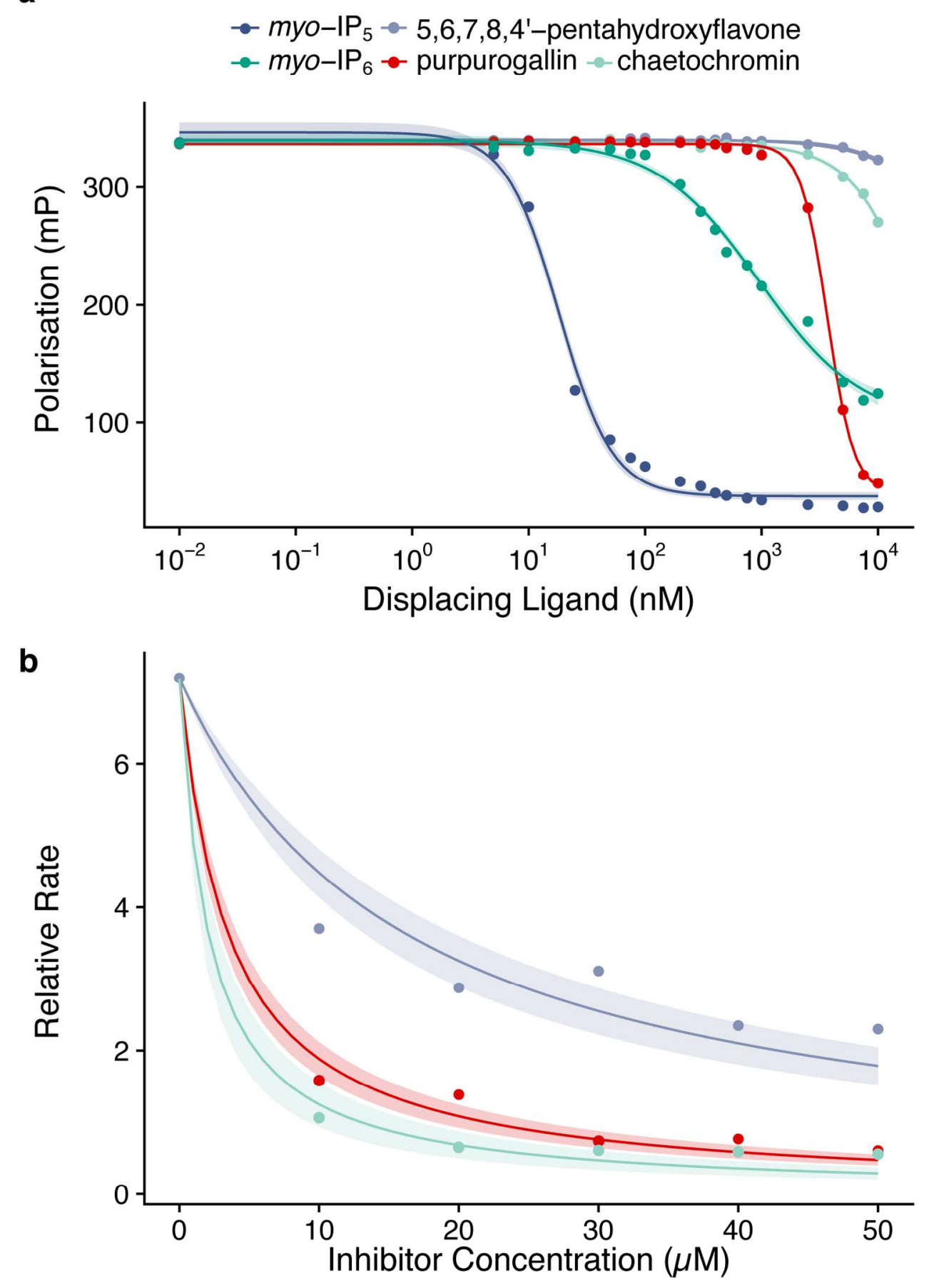

Figure 6. (A) Inhibition of 2-FAM-IP 5 binding to $\operatorname{AtI} P_{5} 2-K$ by myo-Ins $P_{6}$, myo-Ins $(1,3,4,5,6) P_{5}$, purpurogallin, 5, 6, 7,8,4'-pentahydroxyflavone and chaetochromin; (B) Morrison plot of 
inhibition of IP5 2-K by purpurogallin, 5, 6, 7,8,4'-pentahydroxyflavone and chaetochromin; 95\% confidence limits are shown. For comparison myo-Ins $(1,3,4,5,6) P_{5}$ and myo-Ins $P_{6}$ are shown again in $(A)$.

As proof of concept that the displacement assay yields novel active site ligands, we performed assays of the ability of purpurogallin, 5,6,7,8,4'-pentahydroxyflavone and chaetochromin to inhibit the $\mathrm{InsP}_{5}$ kinase activity of AtIP5 2-K, measured as HPLCmonitored production of ADP. Assays constructed to limit substrate depletion to less than $8 \%$, gave, when fitted to the Morrison equation $\left(\mathrm{K}_{m} \mathrm{InsP}_{5}\right.$ set at $\left.22 \mu \mathrm{M}^{21}\right), \mathrm{K}_{\mathrm{i}}$ values (mean, standard error) of $1.08 \pm 0.12 \mu \mathrm{M}, 5.04 \pm 0.74 \mu \mathrm{M}$ and $0.64 \pm 0.09 \mu \mathrm{M}$ for purpurogallin, 5,6,7,8,4'-pentahydroxyflavone and chaetochromin, respectively (Figure 6B).

\section{Ternary structure of AtIP5 2-K with purpurogallin and ADP}

We also sought to verify active site binding of ligands by X-ray crystallography. Cocrystals obtained with purpurogallin at $5 \mathrm{mM}$ gave a structure for the enzyme plus bound ADP which, when refined using data to 2.1 Å resolution (Supporting Table 1), revealed difference Fourier electron density features in the active sites of both monomers in the asymmetric unit (PDB entry 6FL8). Furthermore, this density coincided with that otherwise occupied by inositol phosphate ligands in our structures of ternary complexes described above. Modeling of purpurogallin to this density (Figure 7 and Supporting Information Figures 3,4) and subsequent refinement gave a structure revealing near 'coplanarity' of the rings of purpurogallin with the inositol ring (for consideration of the 


\begin{abstract}
'planarity' of myo-inositol, see $\left.{ }^{36}\right)$. A number of specific protein-ligand interactions are revealed (Figure 7).
\end{abstract}
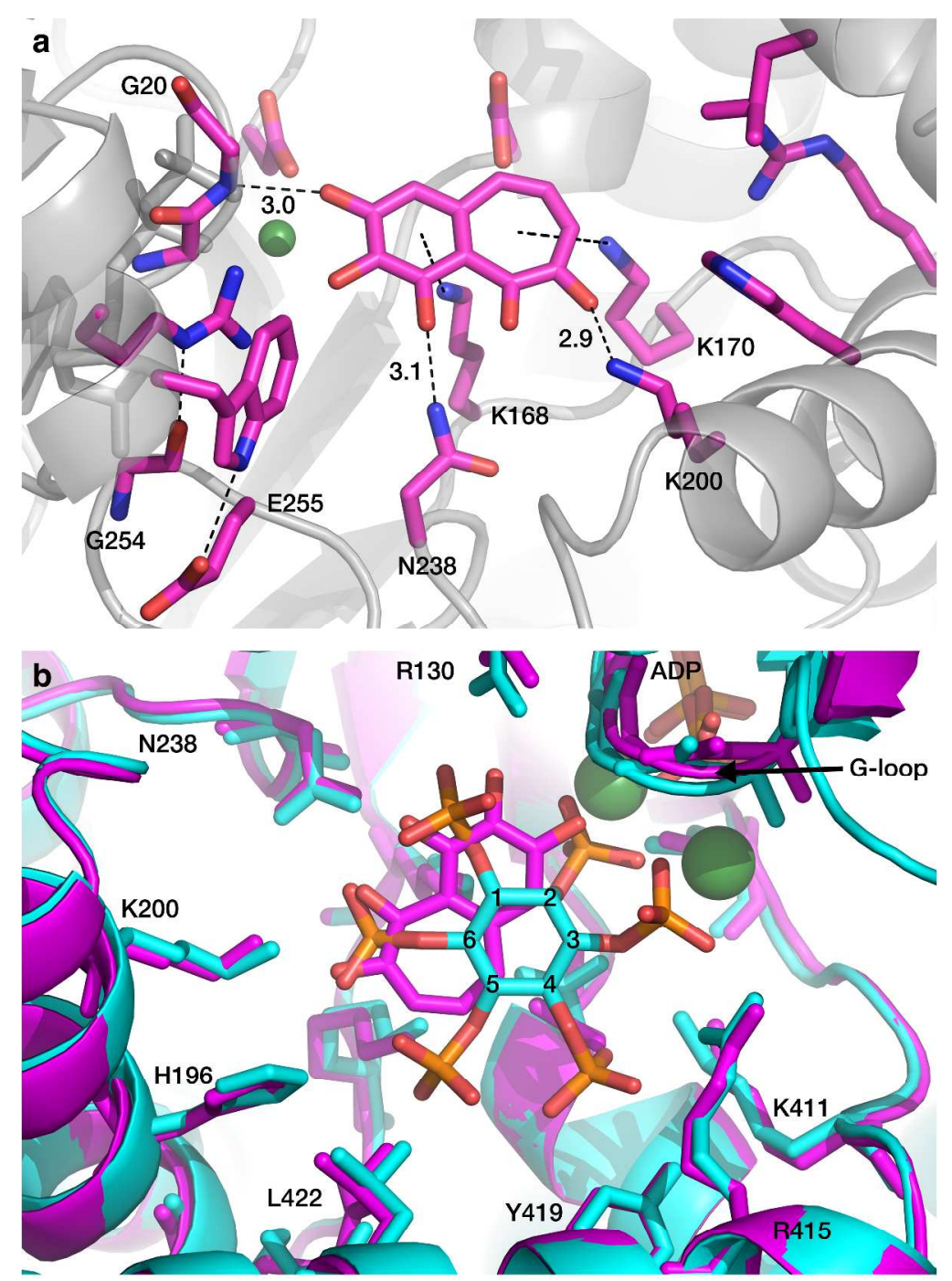

c

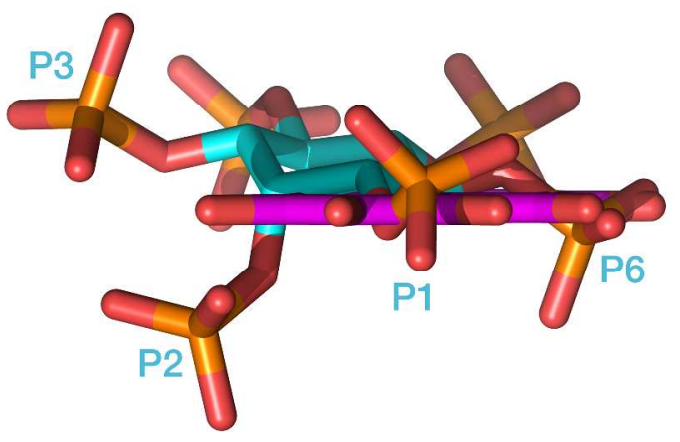


Figure 7. Ternary complex of AtIP5 2-K with purpurogallin and ADP. (A) Interactions of AtIP5 2-K with purpurogallin (magenta). Enzyme polypeptide backbone is shown as a grey cartoon with active site residues in magenta. Hydrogen bonds are shown as dashed lines (distances in Angstrom indicated), cation- $\pi$ interactions as dotted lines. The characteristic interactions of the 'fully-closed' form of the enzyme (between G254 and E255 with W129 and R130) are also shown. (B) AtIP5 2-K active site showing ADP and myo-InsP 6 (cyan) overlaid with purpurogallin (magenta). (C) Orthogonal (to B) projection of myo-InsP 6 (cyan) and purpurogallin (magenta) ligands.

For the 6-membered ring of purpurogallin, a cation- $\pi$ interaction with Lys 168 is observed and hydrogen bonding interactions can be identified with both Gly20 and the sidechain of Asn238 with hydroxyl substitutents to the ring. The positioning of the 7-membered ring is stabilized by a further cation- $\pi$ interaction, this time with Lys 170, while one of the ring's hydroxyl substituents forms a hydrogen bond with the side chain of Lys200. This trio of lysines, Lys168, Lys170 and Lys200, offer conserved interactions with the inositol phosphate ligands of Figure 4 and Supporting Information Figures 3,4.

For ligands of modest affinity such as purpurogallin, careful analysis of the fit of the ligand to electron density maps is important. Consideration of a combination of real space correlation coefficients, real space R-factors and temperature factor data is necessary to assess protein-ligand model quality ${ }^{37}$. These crystallographic statistics for purpurogallin (and for the other ligands described above) are presented in Supporting Information Table 5. The validity of our interpretation for purpurogallin is supported by the observation that the enzyme is found in the 'closed' conformation previously only observed when in 
ternary complex with inositol phosphate ligands and nucleotide. For example, the RMSD against the complex with $m y o$-InsP $\mathrm{P}_{6}$ (PDB entry 6JFK) is $0.60 \AA$ for 397 residues (Supporting Information Table 2), while the RMSDs between the inositide- and nucleotide-coordinating residues of the two structures are $0.52 \AA$ and $0.35 \AA$, respectively (Supporting Information Table 4). Additionally, Gly254 and Glu255 (strand L3) form interactions respectively, with Arg130 and Trp129 (helix $\alpha 6$ ), interactions serving as hallmark features of the 'fully-closed' form of the enzyme ${ }^{14,15}$. Significantly, all published inositide ligand-free structures (i.e. those binding only nucleotide) adopt the 'half-closed' conformation ${ }^{15}$. These data, with those of Figures 5 and 6, reveal a rationale for design of inhibitors that trap protein in the fully closed (ordinarily, inositideand nucleotide co-liganded) state.

\section{Inhibition of labeling of inositol phosphates in vivo}

Finally, to assess the potential of compounds identified by our HTS screen to inhibit AtIP5 2-K in vivo, we radiolabeled Arabidopsis thaliana seedlings with ${ }^{32} \mathrm{P}$ orthophosphate in media containing purpurogallin, 5,6,7,8,4'-pentahydroxy flavone or chaetochromin and quantified inositol phosphates and ATP by HPLC. In labeled Arabidopsis, ATP and $\operatorname{InsP}_{6}$ are by far the strongest labeled peaks, other than unincorporated inorganic phosphate, while myo-Ins $(1,3,4,5,6) \mathrm{P}_{5}$ is the least strongly labeled of $\operatorname{InsP}_{5} \mathrm{~S}{ }^{38}$. Because AtIP5 2-K catalyses transfer of the labeled $\gamma$-phosphate to $m y o-\operatorname{Ins}(1,3,4,5,6) \mathrm{P}_{5}$ to produce $m y o-\operatorname{InsP}_{6}$, analysis of the ratio of labeling $\operatorname{Ins}_{6}$-ATP reveals the effect of the compound on enzyme activity. While we have no test of the permeability to, or metabolism of these compounds by plant cells, both purpurogallin and 
2

3

4

5

6

7

8

9

10

chaetochromin reduced the InsP $\mathrm{P}_{6}-\mathrm{ADP}$ ratio, from $1.33 \pm 0.08$ to $1.04 \pm 0.03(\mathrm{n}=3$; t-test $\mathrm{P}=0.0042)$ and $1.01 \pm 0.11(\mathrm{n}=3$; $\mathrm{t}$-test $\mathrm{P}=0.0152)$, respectively, indicative of inhibition of AtIP5 2-K (Figure 8).

a ATP $\quad \mathrm{IP}_{5} \square \mathrm{IP}_{6}$
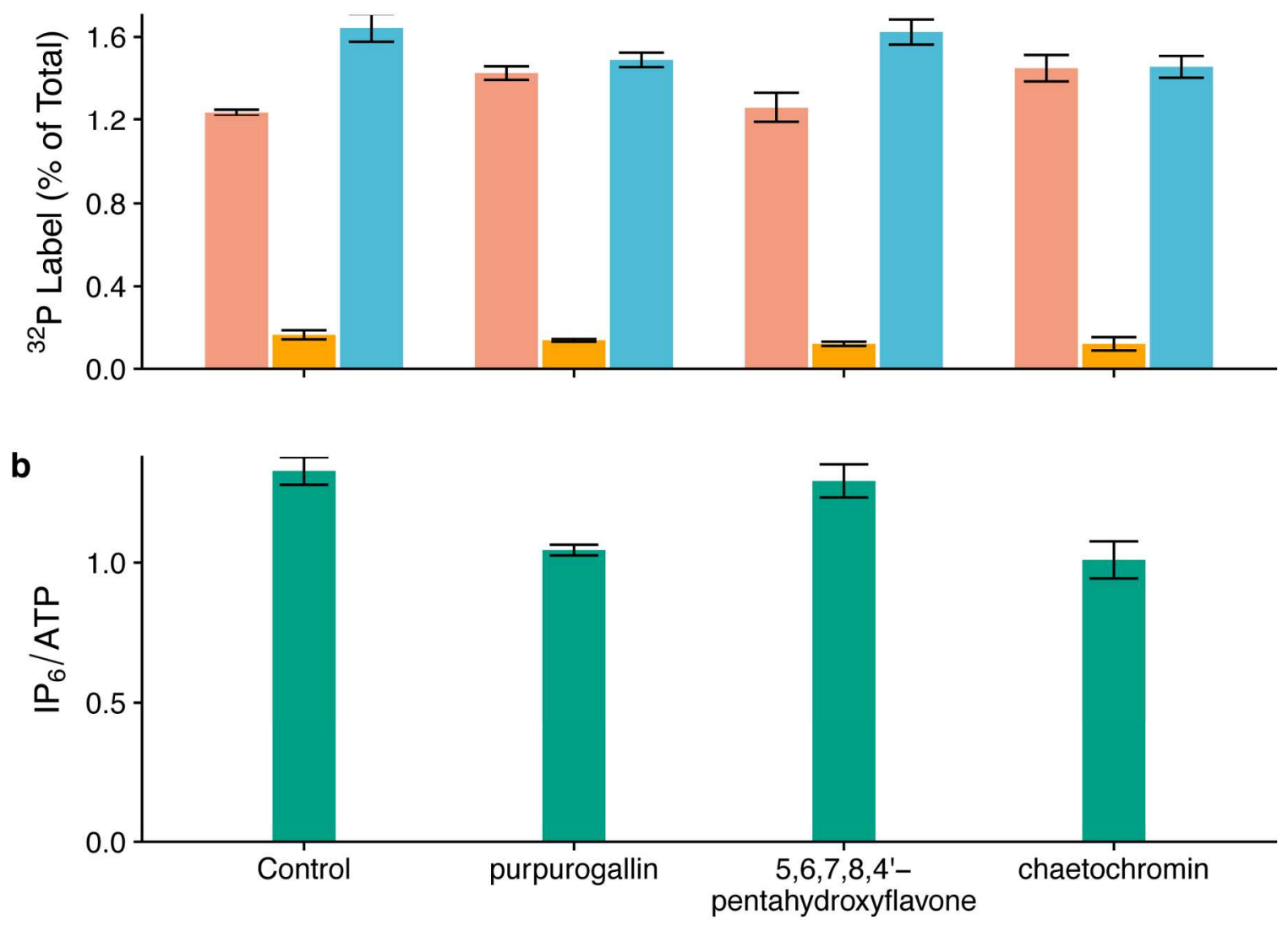

Figure 8. Inhibition of ${ }^{32} \mathrm{P}$ Pi-labeling of inositol phosphates in Arabidopsis. (A) Distribution of label in $A T P, I n s P_{5}$ and Ins $P_{6}$ and $(B)$ ratio of labelling $I P_{6}: A T P, 95 \%$ confidence limits are shown.

\section{CONCLUSIONS}


We have elaborated a fluorescent probe of the active site of inositol pentakisphosphate 2kinase. Screening with which allows identification of potential substrates and inhibitors, confirmed by ligand-binding assays and validated by crystallographic analysis of substrate-enzyme and inhibitor-enzyme complexes. While little attention has been given to the biology of inositol phosphates other than those derived from myo-inositol, other higher inositol phosphates, neo-inositol hexakisphosphate, D-chiro-inositol hexakisphosphate and scyllo-inositol hexakisphosphate are abundant in soils ${ }^{30,39}$. It is possible that they are synthesized by pathways that employ orthologs of IP5 2-K. Indeed, neo-inositol hexakisphosphate and neo-diphosphoinositol phosphates are found in amoeboid organisms ${ }^{40}$. The present work identifies tools for the characterization of enzymes that bind highly phosphorylated inositols and provides a rationale for phosphorylation and dephosphorylation of other epimeric higher inositol phosphates by a ubiquitous metazoan enzyme.

We further show the assay to be amenable to high-throughput screens, and in identification of a ligand that locks the enzyme in the 'fully-closed' conformation provide a basis for ligand-based drug discovery programs using these structures as templates for discovery of potential new pharmacophores that could target higher inositol phosphate metabolism. While the active sites of numerous inositol phosphate kinases are decorated with basic residues that dominate interactions with highly polar inositol phosphate ligands, our work illustrates how the same residues can be recruited to bind ligands of wholly unrelated structure, perhaps rendering such proteins 'druggable'. Finally, we establish the principle of the use of fluorescence polarization-based direct competition assays on inositol phosphate kinases and inositol phosphate-nucleotide 
phosphotransferases of ATP-grasp and IPK folds.

\section{EXPERIMENTAL SECTION}

\section{Chemical synthesis}

Synthesis of 2-FAM-InsP $\mathrm{P}_{5}=2-O-(2-(5$-fluoresceinylcarboxy)-aminoethyl)-myo-inositol 1,3,4,5,6-pentakisphosphate (triethylammonium salt) was as described ${ }^{18}$. The synthesis of neo- $\mathrm{InsP}_{6}$ and D-chiro- $\mathrm{InsP}_{6}$ was described ${ }^{39}$. These inositol phosphates and 2-FAMInsP $P_{5}$ were fully characterized by ${ }^{1} \mathrm{H},{ }^{31} \mathrm{P}$ and ${ }^{13} \mathrm{C}$ NMR spectroscopy and found to be $\geq 95 \%$ purity. 2-FAM-InsP ${ }_{5}$ was additionally analysed by reverse phase analytical HPLC and confirmed to be $\geq 95 \%$ pure. Myo-Inositol 1,3,4,5,6-pentakisphosphate was supplied from $\mathrm{SiChem}$ and $m y o-\mathrm{InsP}_{6}$ from Merck, both with $\geq 98 \%$ purity.

\section{Fluorescence polarization assays}

Fluorescence polarization assays were performed in $50 \mu \mathrm{L}$ volume in Corning, Nonbinding 96-well plates (Product No. 3650 or 3991) or in $20 \mu \mathrm{L}$ volume in Corning, Nonbinding 384-well plates (Product No. 3575). Fluorescence was recorded on a BMG ClarioSTAR plate reader with polarization and fluorescein filter set: $485 \mathrm{~nm}, 12 \mathrm{nM}$; dichroic $505 \mathrm{~nm}$; emission $505 \mathrm{~nm}, 16 \mathrm{~nm}$; and 200 flashes. Data was exported and fitted to a 4-parameter logistic in ggplot2. The initial library screen was performed in 96-well format on a BMG PheraSTAR fitted with a 485/520 nm fluorescence polarisation module. For binding assays, $2 \mathrm{nM} 2-\mathrm{FAM}-\mathrm{InsP}_{5}$ in $20 \mathrm{mM}$ HEPES pH 7.3, $1 \mathrm{mM} \mathrm{MgCl}_{2}$ at $25^{\circ} \mathrm{C}$, was incubated with increasing protein concentrations $(1 \mathrm{nM}-2 \mu \mathrm{M})$. For inhibitor assays, inhibitor $(5 \mathrm{nM}-10 \mu \mathrm{M})$ was titrated against 100nM AtIP5 2-K protein and 2nM 2FAM-IP $_{5}$ in buffer as above. For both, aliquots $(20 \mu 1)$ were dispensed in quadruplicate 
wells and polarization of the probe was measured at $25^{\circ} \mathrm{C}$. Data were rendered in ggplot2 25 .

\section{HPLC}

For assay of phosphotransfer from 2-FAM-IP 5 to ADP, AtIP5 2-K $(1 \mu \mathrm{M})$ was incubated with $50 \mu \mathrm{M}$ ADP and $50 \mu \mathrm{M}$ 2-FAM-IP ${ }_{5}$ in $1 \mathrm{mM} \mathrm{MgCl}_{2}, 20 \mathrm{mM}$ Hepes buffer, $\mathrm{pH} 7.3$ at $25^{\circ} \mathrm{C}$. Reactions were stopped by the addition of an equal volume of $60 \mathrm{mM}\left(\mathrm{NH}_{4}\right)_{2}$ $\mathrm{HPO}_{4}$, $\mathrm{pH} 3.5$ and $20 \mu \mathrm{L}$ aliquots were subjected to anion ion-exchange HPLC on a 2 mm x 250 mm Dionex (Sunnyvale, CA) IonPac AS11 column with 2mm x 50 mM AG11 guard column. The column was eluted at a flow rate of $0.4 \mathrm{ml} . \mathrm{min}^{-1}$ with a gradient of $\mathrm{NaOH}$ delivered from solvent reservoirs containing water (A) and $225 \mathrm{mM} \mathrm{NaOH}$ (B) delivered according to the schedule: time (min), $\% \mathrm{~B} ; 0,0 ; 20,100$. Nucleotides were detected at $260 \mathrm{~nm}$.

For assay of phosphotransfer to ADP, AtIP5 2-K (240 nM) was incubated with $500 \mu \mathrm{M}$ ADP and $50 \mu \mathrm{M}$ myo-, neo- or D-chiro-InsP $\mathrm{P}_{6}$ in $1 \mathrm{mM} \mathrm{MgCl}_{2}, 20 \mathrm{mM}$ Hepes buffer, $\mathrm{pH}$ 7.3 at $25^{\circ} \mathrm{C}$. Reactions were stopped after $240 \mathrm{~min}$ by boiling for $1 \mathrm{~min}$ and $50 \mu \mathrm{L}$ aliquots of a 10 times dilution of the original assay, in water, were subjected to reversephase ion-pair HPLC ${ }^{29}$.

For assay of inhibition of AtIP5 2-K, protein $30 \mathrm{nM}$ was incubated with $50 \mu \mathrm{M}$ ATP and $50 \mu \mathrm{M} \operatorname{Ins}(1,3,4,5,6) \mathrm{P}_{5}$ in $1 \mathrm{mM} \mathrm{MgCl} 2,20 \mathrm{mM}$ Hepes buffer, $\mathrm{pH}$ 7.3. Reactions, at $25^{\circ} \mathrm{C}$, were stopped by the addition of an equal volume of $60 \mathrm{mM}\left(\mathrm{NH}_{4}\right)_{2} \mathrm{HPO}_{4}, \mathrm{pH} 3.5$, and placed on ice before analysis by reverse-phase ion-pair HPLC ${ }^{13}$. Reactions were constructed to limit depletion of ATP to less than $8 \%$. Inhibitors, up to $50 \mu \mathrm{M}$, were pre- 
incubated with enzyme and nucleotide for $20 \mathrm{~min}$ before addition of inositol

phosphate to start the assay.

\section{Radiolabeling of Arabidopsis seedlings}

Arabidopsis thaliana seedlings (ecotype Col-0) were radiolabeled with $370 \mathrm{kBq}$ of ${ }^{32} \mathrm{P}$ orthophosphate in media containing $10 \mu \mathrm{M} \mathrm{KH}{ }_{2} \mathrm{PO}_{4}$ and processed according to ${ }^{38}$.

\section{ANCILLARY INFORMATION}

\section{Supplementary information}

Protein purification, structural and docking methods, probe binding, docking images, structural density images, structural ligand interactions, refinement statistics, pairwise comparisons and definition of binding regions, ligand validation.(PDF)

Molecular formula strings (CSV)

\section{PDB ID codes}

Authors will release the atomic coordinates and experimental data upon article publication. For AtIP5 2-K with ligands (numbered according to SMILES csv file);

$1 \quad$ myo-InsP 5 (PDB entry 6FL3)

$2 \quad m y o-\mathrm{InsP}_{6}(\mathrm{PDB}$ entry $6 \mathrm{FJK})$

$4 \quad$ neo- $\operatorname{InsP}_{5}(\mathrm{PDB}$ entry $6 \mathrm{GFH})$

5 D-chiro-InsP ${ }_{6}$ (PDB entry 6GFG)

6 purpurogallin (PDB entry 6FL8) 


\title{
Homology models
}

\author{
Corresponding Author details \\ c.brearley@uea.ac.uk
}

\section{Author contributions}

H.W., M.G., and K.B. were involved in all the aspects of purifying AtIP5 2-K, library screening and displacement assays. C.A.B. and H.W. performed enzyme assays and HPLC analysis. H.W. and A.M.H. determined the X-ray structures. A.M.R. and Y.H.G. synthesized 2-FAM-IP 5 , neo- and D-chiro-inositol hexakisphosphate. C.A.B., A.M.R. and B.V.L.P. conceived the study and with H.W. and A.M.H. wrote the manuscript.

\section{Acknowledgements}

Funding for the study was obtained by C.A.B. (UEA Proof of Concept Fund and AB Vista Ltd) and B.V.L.P. (Wellcome Trust). B.V.L.P. is a Wellcome Trust Senior Investigator (Grant 101010). K.B.'s PhD was supported by AB Vista. H.W.'s PhD was supported by the UEA. We thank Tom Brearley for assistance in rendering of figures in ggplot2.

\author{
Abbreviations \\ 2-FAM-InsP 5 2-O-(2-(5-fluoresceinylcarboxy)-aminoethyl)-myo-inositol 1,3,4,5,6- \\ pentakisphosphate (triethylammonium salt) \\ IP5 2-K inositol pentakisphosphate 2-kinase \\ AtIP5 2-K Arabidopsis thaliana inositol pentakisphosphate 2-kinase
}




$\begin{array}{ll}\text { PP-InsP } & \text { diphosphoinositol phosphate } \\ \text { PtdIns } & \text { phosphatidyl inositol phosphate } \\ \text { InsP } & \text { myo-inositol 1,3,4,5,6-pentakisphosphate } \\ \text { IPTK4 } & \text { Solanum tuberosum inositol-polyphosphate multikinase } \\ \text { StIPMK } & \text { diphosphoinositol pentakisphosphate kinase }\end{array}$

\section{REFERENCES}

1. Phillippy, B. Q., Ullah, A. H., and Ehrlich, K. C. (1994) Purification and some properties of inositol 1,3,4,5,6-pentakisphosphate 2-kinase from immature soybean seeds, J Biol Chem 269, 28393-28399.

2. Verbsky, J., Lavine, K., and Majerus, P. W. (2005) Disruption of the mouse inositol 1,3,4,5,6-pentakisphosphate 2-kinase gene, associated lethality, and tissue distribution of 2-kinase expression, Proc Natl Acad Sci U S A 102, 8448-8453.

3. York, J. D., Odom, A. R., Murphy, R., Ives, E. B., and Wente, S. R. (1999) A phospholipase C-dependent inositol polyphosphate kinase pathway required for efficient messenger RNA export, Science 285, 96-100.

4. Lee, H. S., Lee, D. H., Cho, H. K., Kim, S. H., Auh, J. H., and Pai, H. S. (2015) InsP6sensitive variants of the Gle1 mRNA export factor rescue growth and fertility defects of the ipk1 low-phytic-acid mutation in Arabidopsis, Plant Cell 27, 417431. 
5. Sarmah, B., Latimer, A. J., Appel, B., and Wente, S. R. (2005) Inositol polyphosphates regulate zebrafish left-right asymmetry, Dev Cell 9, 133-145.

6. Stevenson-Paulik, J., Bastidas, R. J., Chiou, S. T., Frye, R. A., and York, J. D. (2005)

Generation of phytate-free seeds in Arabidopsis through disruption of inositol polyphosphate kinases, Proc Natl Acad Sci U S A 102, 12612-12617.

7. Raboy, V. (2003) myo-Inositol-1,2,3,4,5,6-hexakisphosphate, Phytochemistry 64, 1033-1043.

8. Burton, A., Hu, X., and Saiardi, A. (2009) Are inositol pyrophosphates signalling molecules?, J Cell Physiol 220, 8-15.

9. Stephens, L., Radenberg, T., Thiel, U., Vogel, G., Khoo, K. H., Dell, A., Jackson, T. R., Hawkins, P. T., and Mayr, G. W. (1993) The detection, purification, structural characterization, and metabolism of diphosphoinositol pentakisphosphate(s) and bisdiphosphoinositol tetrakisphosphate(s), J Biol Chem 268, 4009-4015.

10. Saiardi, A., Sciambi, C., McCaffery, J. M., Wendland, B., and Snyder, S. H. (2002) Inositol pyrophosphates regulate endocytic trafficking, Proc Natl Acad Sci US A 99, 14206-14211.

11. Gosein, V., Leung, T. F., Krajden, O., and Miller, G. J. (2012) Inositol phosphateinduced stabilization of inositol 1,3,4,5,6-pentakisphosphate 2-kinase and its role in substrate specificity, Protein Sci 21, 737-742.

12. Gonzalez, B., Banos-Sanz, J. I., Villate, M., Brearley, C. A., and Sanz-Aparicio, J. (2010) Inositol 1,3,4,5,6-pentakisphosphate 2-kinase is a distant IPK member with a singular inositide binding site for axial 2-OH recognition, Proc Natl Acad Sci U S A 107, 9608-9613. 
13. Franco-Echevarria, E., Sanz-Aparicio, J., Brearley, C. A., Gonzalez-Rubio, J. M., and Gonzalez, B. (2017) The crystal structure of mammalian inositol 1,3,4,5,6pentakisphosphate 2-kinase reveals a new zinc-binding site and key features for protein function, J Biol Chem 292, 10534-10548.

14. Gosein, V., and Miller, G. J. (2013) Conformational stability of inositol 1,3,4,5,6pentakisphosphate 2-kinase (IPK1) dictates its substrate selectivity, J Biol Chem 288, 36788-36795.

15. Banos-Sanz, J. I., Sanz-Aparicio, J., Whitfield, H., Hamilton, C., Brearley, C. A., and Gonzalez, B. (2012) Conformational changes in inositol 1,3,4,5,6pentakisphosphate 2-kinase upon substrate binding: role of $\mathrm{N}$-terminal lobe and enantiomeric substrate preference, J Biol Chem 287, 29237-29249.

16. Verbsky, J. W., Wilson, M. P., Kisseleva, M. V., Majerus, P. W., and Wente, S. R. (2002) The synthesis of inositol hexakisphosphate. Characterization of human inositol 1,3,4,5,6-pentakisphosphate 2-kinase, J Biol Chem 277, 31857-31862.

17. Drees, B. E., Weipert, A., Hudson, H., Ferguson, C. G., Chakravarty, L., and Prestwich, G. D. (2003) Competitive fluorescence polarization assays for the detection of phosphoinositide kinase and phosphatase activity, Comb Chem High Throughput Screen 6, 321-330.

18. Riley, A. M., Windhorst, S., Lin, H. Y., and Potter, B. V. L. (2014) Cellular internalisation of an inositol phosphate visualised by using fluorescent InsP5, Chembiochem 15, 57-67. 
19. Rossi, A. M., Riley, A. M., Tovey, S. C., Rahman, T., Dellis, O., Taylor, E. J., Veresov, V. G., Potter, B. V.L., and Taylor, C. W. (2009) Synthetic partial agonists reveal key steps in IP3 receptor activation, Nat Chem Biol 5, 631-639.

20. Watson, P. J., Millard, C. J., Riley, A. M., Robertson, N. S., Wright, L. C., Godage, H. Y., Cowley, S. M., Jamieson, A. G., Potter, B. V.L, and Schwabe, J. W. (2016) Insights into the activation mechanism of class I HDAC complexes by inositol phosphates, Nat Commun 7, 11262.

21. Sweetman, D., Johnson, S., Caddick, S. E., Hanke, D. E., and Brearley, C. A. (2006) Characterization of an Arabidopsis inositol 1,3,4,5,6-pentakisphosphate 2-kinase (AtIPK1), Biochem J 394, 95-103.

22. Voglmaier, S. M., Bembenek, M. E., Kaplin, A. I., Dorman, G., Olszewski, J. D., Prestwich, G. D., and Snyder, S. H. (1996) Purified inositol hexakisphosphate kinase is an ATP synthase: diphosphoinositol pentakisphosphate as a high-energy phosphate donor, Proc Natl Acad Sci U S A 93, 4305-4310.

23. Nair, V.S., Chunfang, G., Janoshazi, A.K., Jessen, H.J., Wang, H., Shears, S.B. (2018) Inositol pyrophosphate synthesis by diphosphoinositol pentakisphosphate kinase-1 is regulated by phosphatidylinositol(4,5)bisphosphate, Bioscience Reports 38 (2)

24. Fridy, P. C., Otto, J. C., Dollins, D. E., and York, J. D. (2007) Cloning and characterization of two human VIP1-like inositol hexakisphosphate and diphosphoinositol pentakisphosphate kinases, J Biol Chem 282, 30754-30762.

25. Ito, K., and Murphy, D. (2013) Application of ggplot2 to Pharmacometric Graphics, CPT Pharmacometrics Syst Pharmacol 2, e79. 
26. Caddick, S. E., Harrison, C. J., Stavridou, I., Johnson, S., and Brearley, C. A. (2007) A lysine accumulation phenotype of ScIpk2Delta mutant yeast is rescued by Solanum tuberosum inositol phosphate multikinase, Biochem J 403, 381-389.

27. Sweetman, D., Stavridou, I., Johnson, S., Green, P., Caddick, S. E., and Brearley, C. A. (2007) Arabidopsis thaliana inositol 1,3,4-trisphosphate 5/6-kinase 4 (AtITPK4) is an outlier to a family of ATP-grasp fold proteins from Arabidopsis, FEBS Lett 581, 4165-4171.

28. Wang H., Falck J. R., Hall T. M. T., Shears S. B. (2011). Structural basis for an inositol pyrophosphate kinase surmounting phosphate crowding. Nat. Chem. Biol. 8, 111-116.

29. Caddick, S. E., Harrison, C. J., Stavridou, I., Mitchell, J. L., Hemmings, A. M., and Brearley, C. A. (2008) A Solanum tuberosum inositol phosphate kinase (StITPK1) displaying inositol phosphate-inositol phosphate and inositol phosphate-ADP phosphotransferase activities, FEBS Lett 582, 1731-1737.

30. Turner, B. L., Paphazy, M. J., Haygarth, P. M., and McKelvie, I. D. (2002) Inositol phosphates in the environment, Philos Trans R Soc Lond B Biol Sci 357, 449-469.

31. Thomas, M. P., Mills, S. J., and Potter, B. V.L. (2016) The "other" inositols and their phosphates: synthesis, biology, and medicine (with recent advances in myoinositol chemistry), Angew Chem Int Ed Engl 55, 1614-1650.

32. Whitfield, H., Riley, A. M., Diogenous, S., Godage, H. Y., Potter, B. V. L., and Brearley, C. A. (2018) Simple synthesis of (32)P-labelled inositol hexakisphosphates for study of phosphate transformations, Plant Soil 427, 149161. 
33. Gosein, V., and Miller, G. J. (2013) Roles of phosphate recognition in inositol 1,3,4,5,6-pentakisphosphate 2-kinase (IPK1) substrate binding and activation, $J$ Biol Chem 288, 26908-26913.

34. Zhang, J. H., Chung, T. D., and Oldenburg, K. R. (1999) A simple statistical parameter for use in evaluation and validation of high throughput screening Assays, J Biomol Screen 4, 67-73.

35. Lambert, J. D., Chen, D., Wang, C. Y., Ai, N., Sang, S., Ho, C. T., Welsh, W. J., and Yang, C. S. (2005) Benzotropolone inhibitors of estradiol methylation: kinetics and in silico modeling studies, Bioorg Med Chem 13, 2501-2507.

36. Parthasarathy, R., and Eisenberg, F., Jr. (1986) The inositol phospholipids: a stereochemical view of biological activity, Biochem J 235, 313-322.

37. Deller, M. C., and Rupp, B. (2015) Models of protein-ligand crystal structures: trust, but verify, J Comput Aided Mol Des 29, 817-836.

38. Kuo, H. F., Hsu, Y. Y., Lin, W. C., Chen, K. Y., Munnik, T., Brearley, C. A., and Chiou, T. J. (2018) Arabidopsis inositol phosphate kinases, IPK1 and ITPK1, constitute a metabolic pathway in maintaining phosphate homeostasis, Plant J. DOI 10.1111/tpj.13974

39. Turner, B. L., Cheesman, A. W., Godage, H. Y., Riley, A. M., and Potter, B. V. L. (2012) Determination of neo- and D-chiro-inositol hexakisphosphate in soils by solution 31P NMR spectroscopy, Environ Sci Technol 46, 4994-5002.

40. Martin, J. B., Laussmann, T., Bakker-Grunwald, T., Vogel, G., and Klein, G. (2000) neo-inositol polyphosphates in the amoeba Entamoeba histolytica, J Biol Chem $275,10134-10140$. 


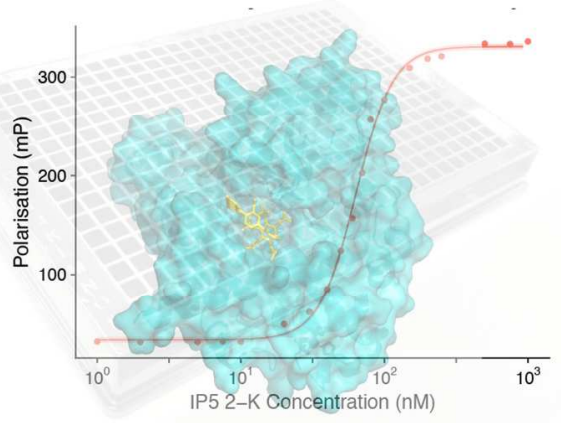

